\title{
Improvement of sorghum seed storage protein digestibility using RNA-interference and genome editing
}

\author{
Elkonin L.A. ${ }^{*}$, Gerashchenkov G.A. ${ }^{2}$, Panin V.M. ${ }^{1}$, Kenzhegulov O.A. ${ }^{1}$, \\ Sarsenova S.Kh. ${ }^{1}$, Rozhnova N.A. ${ }^{2}$, Borisenko N.V. ${ }^{1}$ \\ ${ }^{1}$ Federal Agricultural Research Centre of South-East Region, Saratov, Russia \\ ${ }^{2}$ Institute of Biochemistry and Genetics - Subdivision of the Ufa Federal Research Centre of RAS, Ufa, \\ Russia \\ *email: lelkonin@gmail.com
}

Sorghum (Sorghum bicolor (L.) Moench) is one of the world's most important crops in agricultural production. However, unlike other cereals, sorghum grain has a lower nutritional value, the main reason for which is the resistance of its seed storage proteins (kafirins) to proteolytic digestion. Suppressing the synthesis of individual kafirin subclasses is an effective approach to solve this problem, since distortion of the prolamine synthesis in cereals leads to a rebalancing of the kernel proteome, and to the synthesis of other proteins with a higher content of the essential amino acids, and to increase of endosperm protein digestibility. This goal can be achieved by genetic transformation using the constructs capable for RNAi silencing of kafirin genes or genome editing by introducing mutations into the nucleotide sequences of these genes. In the grain sorghum commercial cultivar Avans, using Agrobacterium-mediated genetic transformation we obtained the RNAi-mutant bearing the genetic construct for RNAsilencing of the $\gamma$-kafirin gene $(g K A F 1)$. The mutant is characterized by complete disappearance of the vitreous endosperm layer, which in this cultivar has dark color and contains tannins interfering with protein digestibility. SDS-PAGE showed that the mutant has reduced content of kafirins. Analysis of endosperm protein digestibility showed significantly higher level of this trait compared to the original non-transgenic cultivar (93 against 57-62\%). The genetic construct for silencing was inherited under self-pollination and in hybridization with CMS-lines. In order to use genome editing we have created two series of vectors, which contain genomic target motifs (23 bp sequences) of the $\alpha$-kafirin (p1C, p2C, p05, p06) and $\gamma$-kafirin (p3C, p4C, p07, p08) genes, Cas 9 gene, and the marker gene bar. Using these vectors, we have obtained transgenic sorghum plants, which are currently investigated.

Acknowledgments: The work was funded in part by the Russian Foundation for Basic Research, grant 19-016-00117. 